\title{
Water and Sanitation in Schools: A Systematic Review of the Health and Educational Outcomes
}

\author{
Christian Jasper ${ }^{1}$, Thanh-Tam Le ${ }^{2}$ and Jamie Bartram ${ }^{1, *}$
}

1 The Water Institute, Gillings School of Global Public Health, University of North Carolina at Chapel Hill, 135 Dauer Drive, CB \#7431, Chapel Hill, NC 27599, USA;

E-Mail:cjasper@wakehealth.edu

2 Department of Biology, University of North Carolina at Chapel Hill, 120 South Road, Chapel Hill, NC 27599, USA; E-Mail: let@email.unc.edu

* Author to whom correspondence should be addressed; E-Mail: jbartram@email.unc.edu; Tel.: +1-919-966-3934; Fax: +1-919-966-7911.

Received: 4 May 2012; in revised form: 14 July 2012 / Accepted: 17 July 2012 /

Published: 3 August 2012

\begin{abstract}
A systematic review of the literature on the effects of water and sanitation in schools was performed. The goal was to characterize the impacts of water and sanitation inadequacies in the academic environment. Published peer reviewed literature was screened and articles that documented the provision of water and sanitation at schools were considered. Forty-one peer-reviewed papers met the criteria of exploring the effects of the availability of water and/or sanitation facilities in educational establishments. Chosen studies were divided into six fields based on their specific foci: water for drinking, water for handwashing, water for drinking and handwashing, water for sanitation, sanitation for menstruation and combined water and sanitation. The studies provide evidence for an increase in water intake with increased provision of water and increased access to water facilities. Articles also report an increase in absenteeism from schools in developing countries during menses due to inadequate sanitation facilities. Lastly, there is a reported decrease in diarrheal and gastrointestinal diseases with increased access to adequate sanitation facilities in schools. Ensuring ready access to safe drinking water, and hygienic toilets that offer privacy to users has great potential to beneficially impact children's health. Additional studies that examine the relationship between sanitation provisions in schools are needed to more adequately characterize the impact of water and sanitation on educational achievements.
\end{abstract}


Keywords: water; school; menstruation; drinking; sanitation; handwashing

\section{Introduction}

The United Nations Millennium Development Goal 2.A is to "ensure that, by 2015, children everywhere, boys and girls alike, will be able to complete a full course of primary schooling” [1]. Inadequate water and sanitation facilities in the school environment have been reported as a major hindrance towards achievement of this goal. Many schools in developing and developed countries lack adequate water and sanitation services, with associated potential detrimental effects on health and school attendance [2,3].

The goal of this review is to characterize how inadequacies in water and sanitation in the school environment have the potential to or are impacting the health of children and their attendance in schools. We sought to identify all claimed effects of adequate or inadequate water and sanitation access in the school environment by cataloguing peer-reviewed journal articles on the subject, defining the scope of effects, and highlighting possible future research directions within the field. The school environment represents an important setting because many children's social habits and behaviors are learned at school. School WASH interventions improve overall sanitation, hygiene and daily water intake in both educational and non-educational environments [4]. According to the World Health Organization, $11 \%$ more girls attend school when sanitation is available [5]. Many children in both developing and developed nations spend time absent from schools due to diseases contracted within the school environment [6].

\section{Methods}

\subsection{Criteria for Inclusion}

Published peer reviewed literature was screened and reviewed and peer reviewed journal articles that documented an educational or health effect associated with provision or absence of water and/or sanitation in schools selected. These impacts include an increase or decrease in school attendance, school dropouts, or any type of physical, social or psychological illness. The review was restricted to studies that explicitly explored the effects of the provision or absence of water, sanitation, and related hygiene materials such as soap, towels, and toilet paper in the school environment; studies that only examined the effects of behavior changes were excluded. Dissertations were not included. Articles without abstracts or full texts available were not included. Studies concerning day care centers were excluded. Studies on hand sanitizers were excluded.

We categorized 'water' interventions as either those for hand washing-including water, wash basins, soap, and drying devices, or for drinking. Studies considering only the impact of fluoride in drinking water were also excluded from the review, as the effects of fluoride on oral health in schools have been widely studied. Sanitation was defined as the availability of facilities to urinate or defecate (private, safe toilets, latrines, and availability of toilet paper) or as facilities for women and girls to manage menstruation (private location, and means for management or disposal of menstrual hygiene 
materials). Studies on the impact of availability of sanitary napkins were not included. The outcomes targeted by this review included health and educational outcomes. Health effects included in the study encompassed all of the defined social health, mental and physical health topics recognized by the National Institute of Health. Educational outcomes included school attendance and academic performance.

Studies were classified into seven non-exclusive categories: intervention trials, randomized control trials, observational studies, participatory research studies, descriptive studies, cross-sectional studies and outbreak investigations. Studies were also organized by economic status and field topic in order to better organize the results of the search.

\subsection{Search Strategy for Identification of Studies}

The following major scientific, electronic databases were searched during the months of October through December 2010: PubMed, Embase, Web of Science, the Cochrane Library, Science Direct, and Google. In March 2012 a follow-up scan for subsequently published papers was conducted and five articles that met the inclusion criteria were added to the review.

The primary search was based on the keywords: Schools and Water or Sanitation, Gender and Water or Sanitation, Girls and Water or Sanitation, Menstruation and Water or Sanitation, School Absenteeism and Water or Sanitation, School Health Policies and Water or Sanitation, WASH (Water, Sanitation, and Hygiene) and Schools. All references in the bibliographies of included documents were also systematically searched for relevant documents. The study was restricted to documents for which an abstract and article in English was available.

The search included no time or location restrictions. Studies not written in English, or without an English translation available, were not included in this review. A secondary reviewer completed the review independently. Consensus was reached between primary and secondary reviewers in all cases of initial disagreement.

\section{Results}

\subsection{Inclusion, Exclusion and Yielded Studies}

The primary search identified 3,485 publications whose titles discussed water provision, water quality or sanitation facilities in schools. The majority of these references came from scientific databases $(n=3,312)$, with the majority from PubMed $(n=2,025)$. The secondary screening based on abstract identified 471 relevant references. Thirty-nine articles met the inclusion criteria for the tertiary, full-text, review. Bibliographies of these articles revealed an additional six articles. Four of the 39 included studies were excluded from the library due to duplication in multiple papers; in these cases the most comprehensive article from each of these studies was included. Forty-one papers were included in the initial systematic review. Six more studies were added after the initial review, making forty-seven included studies used in data analysis $(n=47)$ (Figure 1). 
Figure 1. Results during each screening phase and final number of included documents.

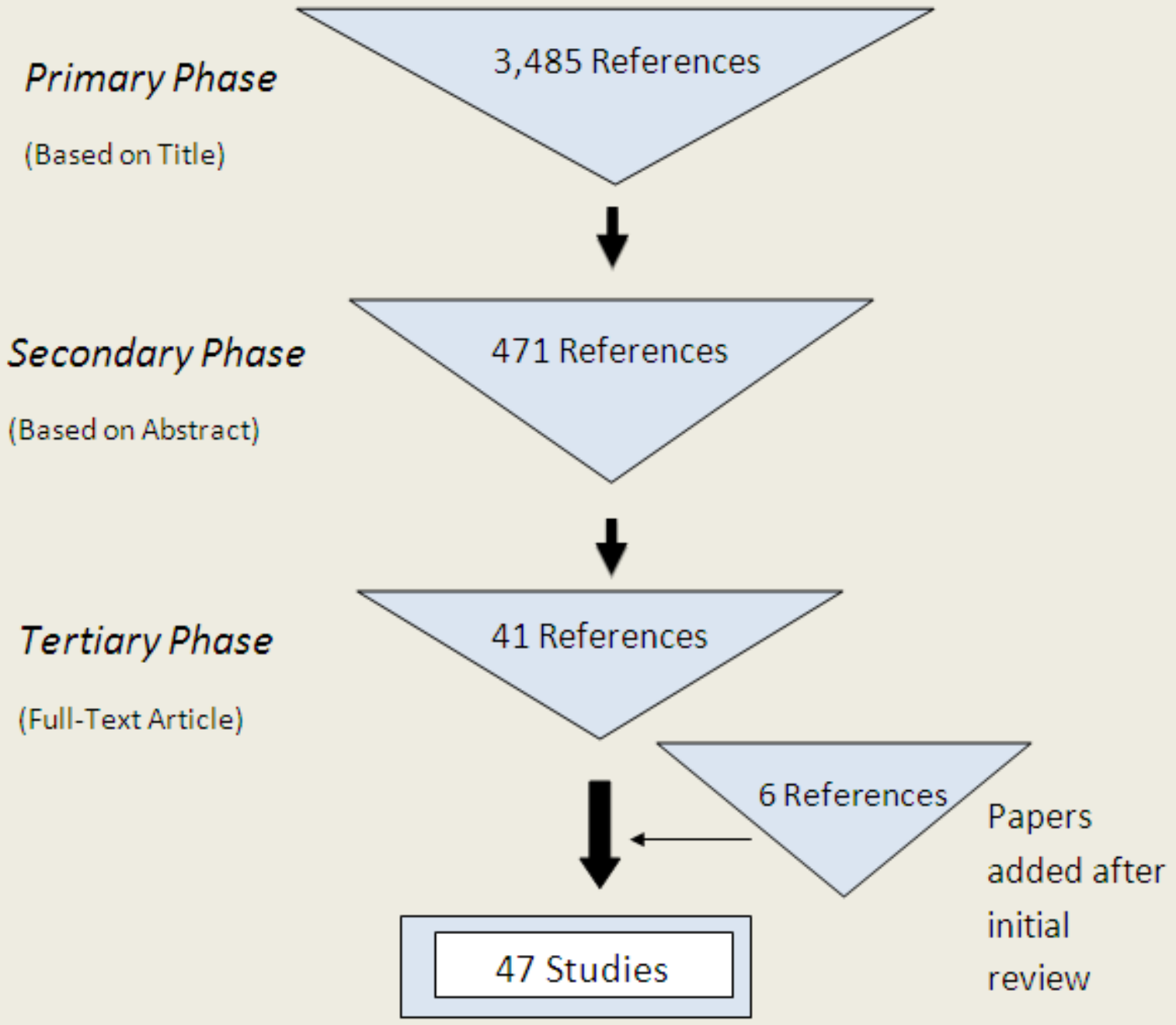

Table 1. Field Foci addressed in included papers $(n=47)$. Percentages rounded to the nearest whole number.

\begin{tabular}{cc}
\hline Field Foci & Percentage (\%) \\
\hline Water for Drinking & 23 \\
Water for Handwashing & 15 \\
Water for Drinking and Handwashing & 11 \\
Water for Sanitation & 13 \\
Sanitation for Menstruation & 8 \\
Water and Sanitation & 30 \\
\hline
\end{tabular}

Of the forty-seven papers, eleven addressed drinking water (23\%), seven addressed water for handwashing (15\%), five addressed providing water for drinking and handwashing (11\%), six addressed sanitation (13\%); four papers addressed sanitation related to menstruation facilities (8\%); and fourteen addressed providing water and sanitation combined in schools (30\%) (Table 1). 
Many of the studies utilized more than one source of data. Twelve of the forty-seven studies included an experimental intervention (25\%); twelve studies used interviews, questionnaires, or focus group and site observation (25\%); fourteen studies were analyses of publicly-available data or questionnaires (30\%); two studies performed solely site observations (4\%); and nine studies included microbiological analyses of student stool samples, observations of sites and/or a questionnaire (19\%).

The forty-seven included studies comprised nine intervention trials (19\%); four randomized control trials (9\%); one observational study (2\%); one participatory research study (2\%); four descriptive studies (9\%); twenty-six cross-sectional studies (55\%); and two outbreak investigations (4\%) (Table 2). Characteristics of studies included in the review are highlighted in Table 3.

Table 2. Study types included from the forty-seven included studies $(n=47)$. Percentages rounded to the nearest whole number.

\begin{tabular}{cc}
\hline Study Type & Percentage (\%) \\
\hline Intervention & 19 \\
Randomized Control Trial & 9 \\
Observational Study & 2 \\
Participatory Research Study & 2 \\
Descriptive Study & 9 \\
Cross-Sectional Study & 55 \\
Outbreak Investigation & 4 \\
\hline
\end{tabular}

Table 3. Characteristics of studies included in the review, grouped by field examined. Dash marks indicate items not reported in the studies.

\begin{tabular}{|c|c|c|c|c|c|c|}
\hline \multirow[b]{2}{*}{ Study } & \multirow{2}{*}{$\begin{array}{l}\text { Reference } \\
\text { Number }\end{array}$} & \multirow[b]{2}{*}{ Design } & \multirow[b]{2}{*}{ Location } & \multicolumn{2}{|c|}{ Sample Size } & \multirow{2}{*}{$\begin{array}{c}\text { Study Time } \\
\text { (months) }\end{array}$} \\
\hline & & & & $\begin{array}{l}\text { \# schools } \\
\text { sampled }\end{array}$ & $\begin{array}{c}\text { \# of participants } \\
\text { sampled }\end{array}$ & \\
\hline \multicolumn{7}{|l|}{ Water for Drinking } \\
\hline Berkowitz (1995) & [7] & Descriptive Study & United States & 37 & 49 & - \\
\hline Bryant (2004) & [8] & Cross-sectional & United States & 292 & - & 8 \\
\hline Costa et al. (1997) & [9] & Cross-sectional & United States & 1 & 116 & - \\
\hline Haines \& Rogers (2003) & [3] & Cross-sectional & United Kingdom & 243 & - & 2 \\
\hline Hunter et al. (2004) & {$[10]$} & Cross-sectional & United Kingdom & 127 & - & Survey \\
\hline Kaushik et al. (2007) & [11] & Cross-sectional & United Kingdom & 6 & 298 & 3 \\
\hline $\begin{array}{l}\text { Loughridge, J. L. and } \\
\text { Barratt, J. (2005) }\end{array}$ & [12] & Intervention & United Kingdom & 3 & 2,965 & 3 \\
\hline Muckelbauer et al. (2009) & [13] & $\begin{array}{l}\text { Randomized } \\
\text { Control Trial }\end{array}$ & Germany & 32 & 2,950 & 8 \\
\hline Patel et al. (2011) & [14] & Intervention & United States & 1 & 881 & 2 \\
\hline Sathyanarayana et al. (2006) & {$[15]$} & Descriptive Study & United States & 71 & - & 24 \\
\hline Wallis \& Dorman (1970) & [16] & Intervention & United Kingdom & 2 & 427 & 3 \\
\hline \multicolumn{7}{|c|}{ Water for Drinking and Handwashing } \\
\hline Blanton (2010) & [17] & Intervention & Kenya & 17 & 666 & 13 \\
\hline Chen et al. (2001) & {$[18]$} & $\begin{array}{c}\text { Outbreak } \\
\text { investigation }\end{array}$ & Taiwan & 1 & 730 & 1 \\
\hline Freeman et al. (2011) & [4] & Intervention & Kenya & 135 & 6,063 & 2 \\
\hline Migele et al. (2007) & [19] & Intervention & Kenya & 1 & 380 & 12 \\
\hline O’Reilly et al. (2008) & [20] & Intervention & Kenya & 9 & 390 & 12 \\
\hline
\end{tabular}


Table 3. Cont.

\begin{tabular}{|c|c|c|c|c|c|c|}
\hline \multirow[b]{2}{*}{ Study } & \multirow{2}{*}{$\begin{array}{l}\text { Reference } \\
\text { Number }\end{array}$} & \multirow[b]{2}{*}{ Design } & \multirow[b]{2}{*}{ Location } & \multicolumn{2}{|c|}{ Sample Size } & \multirow[b]{2}{*}{$\begin{array}{l}\text { Study Time } \\
\text { (months) }\end{array}$} \\
\hline & & & & $\begin{array}{l}\text { \# schools } \\
\text { sampled }\end{array}$ & $\begin{array}{c}\text { \# of participants } \\
\text { sampled }\end{array}$ & \\
\hline \multicolumn{7}{|l|}{ Sanitation for Menstruation } \\
\hline Abrahams et al. (2006) & {$[21]$} & Cross-sectional & South Africa & 3 & - & 4 \\
\hline Jones et al. (2001) & [22] & Cross-sectional & United Kingdom & 344 & - & Survey \\
\hline $\begin{array}{l}\text { Menstrual Hygiene } \\
\text { Subcommittee of the Medical } \\
\text { Women's Federation (1949) }\end{array}$ & [23] & Cross-sectional & United Kingdom & 112 & - & Survey \\
\hline Sommer (2010) & {$[24]$} & $\begin{array}{c}\text { Participatory } \\
\text { Research } \\
\end{array}$ & Tanzania & Unknown & 96 & 1.5 \\
\hline \multicolumn{7}{|l|}{ Water for Handwashing } \\
\hline Bowen et al. (2007) & {$[25]$} & $\begin{array}{l}\text { Randomized } \\
\text { Control Trial } \\
\end{array}$ & China & 87 & 3,962 & 5 \\
\hline Burr et al. (1978) & [26] & Cross-sectional & United Kingdom & 291 & 54,749 & 1 \\
\hline Freeman and Clasen (2011) & [27] & Intervention & Southern India & 60 & 517 & 12 \\
\hline Lopez-Quintero et al. (2009) & [28] & Cross-sectional & Colombia & 225 & 2,042 & - \\
\hline Rosen et al. (2006) & [29] & $\begin{array}{l}\text { Randomized } \\
\text { Control Trial }\end{array}$ & Israel & 40 & 1029 & 2.5 \\
\hline Scott and Vanick (2007) & {$[30]$} & Cross-sectional & United States & 1 & 994 & 1.5 \\
\hline Talaat et al. (2011) & {$[31]$} & $\begin{array}{l}\text { Randomized } \\
\text { Control Trial }\end{array}$ & Egypt & 60 & 44,451 & 4 \\
\hline \multicolumn{7}{|l|}{ Sanitation } \\
\hline $\begin{array}{l}\text { Barnes and Maddocks } \\
(2002)\end{array}$ & {$[32]$} & Descriptive study & United Kingdom & 65 & 85 & 2 \\
\hline Duran-Narucki, (2008) & [33] & Cross-sectional & United States & 95 & - & 12 \\
\hline $\begin{array}{l}\text { Lundblad and Hellstrom } \\
(2005)\end{array}$ & {$[34]$} & Cross-sectional & Sweden & 5 & 385 & $\begin{array}{c}\text { Survey } \\
\text { during } 2001 \\
\end{array}$ \\
\hline Mwanri et al. (2001) & [35] & Cross-sectional & Tanzania & 76 & 207 & 1 \\
\hline $\begin{array}{l}\text { Samwel and Gabizon } \\
\text { (2009) }\end{array}$ & {$[36]$} & Descriptive study & $\begin{array}{c}\text { Eastern European } \\
\text { nations }\end{array}$ & unknown & unknown & Unknown \\
\hline Upadhyay et al. (2008) & [37] & Cross-sectional & New Zealand & 46 & 14,620 & Survey \\
\hline \multicolumn{7}{|c|}{ Combined Water and Sanitation } \\
\hline Adegbenro (2007) & [38] & Intervention & Nigeria & 10 & - & 36 \\
\hline Curin and Pavic (1999) & [39] & Cross-sectional & Croatia & 42 & 138 & 12 \\
\hline Ebong (1994) & [40] & Cross-sectional & Nigeria & 1 & 192 & 3 \\
\hline Fujiwara-Pichler et al. (2006) & [41] & Cross-sectional & United Kingdom & 65 & 92 & 1 \\
\hline Hughes et al. (2004) & [42] & Cross-sectional & 14 Pacific Islands & 27 & 3,826 & 16 \\
\hline Jewkes et al. (1990) & [43] & Cross-sectional & United Kingdom & 37 & 16 & 3 \\
\hline Koopman (1978) & [6] & Cross-sectional & Colombia & 31 & 8,444 & 1.5 \\
\hline Midzi et al (2011) & [44] & Cross-sectional & Zimbabwe & 4 & 172 & 1 \\
\hline Perez (2010) & [45] & Cross-sectional & United Kingdom & 130 & - & Survey \\
\hline Rajaratnam et al. (1992) & {$[46]$} & $\begin{array}{c}\text { Outbreak } \\
\text { investigation }\end{array}$ & United Kingdom & 1 & 283 & $\sim 2$ \\
\hline Thomas and Tillett (1973) & {$[47]$} & $\begin{array}{l}\text { Observational } \\
\text { Analytic study }\end{array}$ & United Kingdom & 34 & - & 1951-1968 \\
\hline Udo and Eja (2004) & [48] & Cross-sectional & Nigeria & 3 & 593 & 4 \\
\hline $\begin{array}{l}\text { Ulukanligil and Seyrek } \\
(2003)\end{array}$ & [49] & Cross-sectional & Turkey & 3 & 1,820 & 1 \\
\hline Vernon et al. (2003) & {$[50]$} & Cross-sectional & $\begin{array}{c}\text { United } \\
\text { Kingdom/Sweden }\end{array}$ & $10 / 7$ & $394 / 157$ & Survey \\
\hline
\end{tabular}


The health, cognitive and educational outcomes catalogued in the studies were: infectious diseases (including helminth infections, diarrhea, respiratory and other communicable diseases) $(\mathrm{n}=20)$; gastrointestinal issues including constipation, incontinence, and urinary tract infections related to avoidance ( $(n=7)$; physical harm, $(n=2)$; dehydration $(n=6)$; obesity $(n=2)$; neuro-cognitive impacts including mental performance ( $n=7$ ); psychological outcomes such as shame or discomfort to use the toilet $(n=5)$; and absenteeism $(n=8)$. Seven studies documented outcomes of schools failing to serve as role models on hygiene (thereby undermining the efforts of teaching hygiene, which was not quantified) $(\mathrm{n}=7)$. Educational outcomes included educational achievements and school attendance, while eight studies report absenteeism, only one study analyzed academic performance as an educational outcome [33] (Figure 2).

Figure 2. Effects catalogued in included studies $(n=47)$.

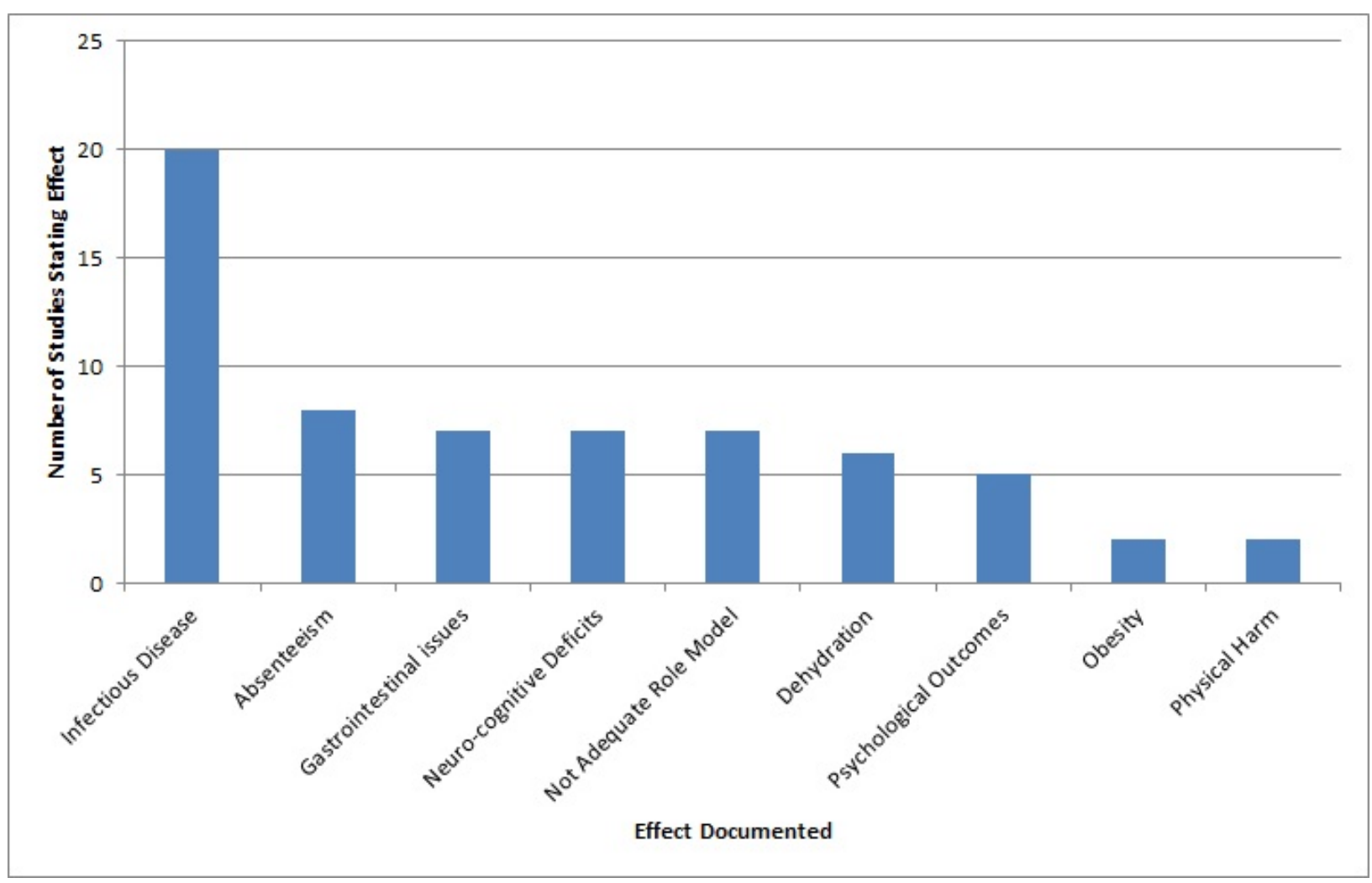

Studies were grouped into categories to more effectively describe the results. Articles were also analyzed to determine the differences in responses in developing vs. developed regions, as classified by the United Nations Statistical Division. However, the studies revealed similarities in reported inadequacies in facilities and in the stated benefits of provision of water and sanitation services [51]. This can be partially attributed to the locations studies were performed within the developed region. Many of the studies in developed countries were self-reported or designated as either from socially deprived, rural or overcrowded urban areas. All studies in South Wales $(n=12)$ were also considered to be conducted in deprived areas because of the water conditions reported in that part of the United Kingdom, including water shortages and inadequate sanitation facilities $[11,12,26]$. 


\subsection{Water for Drinking}

Eleven studies investigated drinking water provision and five examined both water for drinking and for handwashing combined [3,4,7-20]. All studies that exclusively investigated water for drinking were conducted in developed countries: ten studies in the United Kingdom and in the United States and one in Germany. Seven of the eleven studies measured the change in water consumption from increased water provision in schools $[3,10,11,13,14,16]$, while four focused on the water quality issues relating to lead in school water [7-9,15]. All eleven studies reported inadequacies in provision of water for drinking and benefits of improving drinking-water provision in schools.

Two survey studies in schools in the United Kingdom documented inadequate water facilities such as water fountains potentially leading to inadequate hydration $[3,10]$. These studies cite the established effects of dehydration on health outcomes, such as decreased physical activity, mental capacity, and urinary tract infections. Three intervention studies documented a statistically-significant increase in water consumption when school children were allowed free access to water in school [11-13]. One further study, a randomized control trial, reported a 31\% reduction in the risk of overweight associated with providing drinking water and education in schools in Germany [13].

In relation to water quality, four studies concerned lead in drinking-water fountains in schools in the United States [7-9,15]. These studies indicate the potential for significant lead exposure to occur due to lead contamination of school drinking water sources. The neurotoxic effects of lead on children, even at low doses, are well understood [52,53]. Though lead was found in school drinking water sources, blood lead levels were not tested in students in three out of the four studies [7-9]. Sathyanarayana et al., in 2006 tested the blood lead levels in students in a Washington State school after reports of lead levels above USEPA guidelines [15]. The study found that lead in school drinking water was not a significant source of lead exposure for students; the worst-case scenario geometric mean blood lead levels for 5-6 year old children in these schools ranged from 1.7-5.0 $\mu \mathrm{g} / \mathrm{dL}$; which is considered low for the state [15].

\subsection{Water for Handwashing and Water for Drinking and Handwashing Combined}

Seven studies examined handwashing in schools while five studies examined both water for drinking and for handwashing combined [25,26,28-31]. All studies used surveys or questionnaires, and validated findings through triangulation of data methods such as site observations, and analysis of school records. Three of the five studies that exclusively examine handwashing were conducted in developed countries [31,33,34], and all of the studies examining water for drinking and handwashing combined were conducted in developing countries [4,17-20]. This body of literature provided evidence for provision of water for handwashing and handwashing materials such as soap related to decreased absenteeism and reported illnesses as well as to increased handwashing knowledge.

Schools with scarce supplies for handwashing — such as water provision, soap, or towels—reported less handwashing $[28,30]$. Scarcity of supplies was noted in a United States survey study in 2007 on a college campus, revealing that $59 \%$ of residence halls on campus provided no soap and $90 \%$ no paper towels Thirty one percent of respondents indicated they did not wash their hands due to lack of supplies for handwashing [34]. The findings of the survey by Lopez-Quintero et al., in Colombia, 
indicate that children with access to handwashing materials were three times as likely to consistently wash their hands before eating and after toilet usage. In addition, those who reported proper handwashing (before meals, after toilet use) were statistically significantly less likely to report illness such as gastrointestinal and respiratory symptoms, and 20\% less likely to be absent [28]. These surveys provide some evidence for a potential link between provision of handwashing services and handwashing behavior in school environments.

Three randomized control trials targeted at increasing provision of water for handwashing in Israel, China and Egypt reported dissimilar findings [25,29,31]. In their study in Israel, Rosen et al., performed a quasi-blinded handwashing study and found no significant change in rates of communicable illness or absenteeism despite sustained handwashing behavior after six months [29]. Bowen et al., conducted an experimental handwashing study in China in which the intervention groups experienced statistically significant lower rates of illness and of absenteeism [25]. Talaat et al., conducted a handwashing and education intervention in Cairo, Egypt and reported statistically significant declines in absences caused by illnesses such as diarrhea, conjunctivitis and laboratory confirmed cases of influenza [31].

Three of the six studies that investigated the combined effects of drinking water provision as well as water for handwashing reported decreased absenteeism and illness rates due to inadequate sanitation materials and facilities [17-20]. Blanton et al., performed interventions at seventeen Kenyan schools which provided handwashing and drinking water treatment sources and education of teachers [17]. They found a significant increase in household water treatment practices that was sustained over one year and reported a $26 \%$ decrease in pupil absenteeism after the implementation of the school-based programs [17]. Migele et al., found a statistically significant decrease in visits to the school nurse for diarrheal diseases in response to their interventions in Kenya which involved providing drinking water treatment and handwashing stations [19].

\subsection{Sanitation}

Six studies met the pre-defined search criteria for sanitation [32-37]. Five of the studies were conducted in a developed nation [32-34,36,37] and one in a developing [35]; all six document inadequacies in sanitation provision and the benefits of provision in schools.

Samwel and Gabizon highlight the need to build sustainable toilet facilities indoors in rural areas in Eastern European nations due to avoidance of outdoor toilets located far from the school buildings [36]. Outdoor toilets surveyed also displayed inadequate sanitation; many facilities had insufficient water availability and floors covered with urine which froze in winter [36]. Surveys by Barnes and Maddocks in the United Kingdom and Lundblad et al., in Sweden also documented avoidance of toilets observed as smelly, unclean and lacking privacy [32,34].

Overcrowding in schools was also associated with the avoidance of toilets. Students were reported to avoid using the toilet due to the anxiety of waiting in line during recess or lack of privacy [37].The avoidance of toilets may contribute to a higher risk of associated continence-related issues like urinary tract infections.

There was only one study that examined academic performance as an educational outcome, a study assessing the condition of school sanitation facilities in New York City by Duran-Narucki [33]. The study found that the condition of schools, as assessed using multiple indicators including school 
sanitation facilities, was related to students' academic success and school attendance. In rundown school buildings students attended fewer days and exhibited poorer performance on math and English standardized tests [33].

\subsection{Sanitation for Menstruation}

Four studies focusing on the provision of water and sanitation facilities for menstruation management in the school environment met the search criteria [21-24]. Two were conducted in developing countries - South Africa [21] and Tanzania [24] — and two in a developed, the United Kingdom [22,23].

All four studies documented female discomfort in the school environment during menses due to inadequacies in the assurance of privacy, disposal of materials for menstruation, or sufficient school water and sanitation facilities. Economically developed countries may have sanitation facilities that enable females to privately manage menses due to an abundant supply of clean water, privacy, affordable sanitary materials and undergarments and may also have supportive female teachers and school nurses for managing menses [24]. However, deficiencies in sanitation facilities to manage menstruation in schools in the United Kingdom were reported in two cross-sectional studies [22,23]. Post-pubescent female schoolgirls in Tanzania and South Africa reported challenges to travel to and to attend school during menses due to the inability to afford sanitary materials as well as inadequate school facilities such as no running water or broken doors [21,24]. School girls in South Africa also reported a fear of using sanitation facilities due to sexual attacks in school toilets located far from the school building as well as avoiding schools during menstruation [21].

\subsection{Combined Effects of Water and Sanitation}

Fourteen studies focus on the combined effects of water and sanitation in schools [6,38-50]. Six of these studies were conducted in developed countries [41,43,45-47,50]; all of the studies document inadequacies in water and sanitation provision and the impact of provision in schools sampled. One observational study, eleven cross-sectional and two experimental studies were present in this body of literature.

Three studies reported inadequate water and sanitation facilities in schools through surveys and commentaries $[41,43,45]$. Six studies reported evidence on the lack of adequate sanitation facilities associated with greater risk of gastrointestinal and communicable infections [6,41,43,45,46,50]. Koopman's 1978 epidemiologic study in Colombia reported statistically significant evidence for a causal relationship between the adequacy of toilets (toilet facilities that are not easily broken by students, adequate supply of water, cleanliness, and provision of toilet paper, soap and towels for drying) and diarrhea and vomiting in the schools observed [6]. In an outbreak investigation, Rajaratnam et al., documented that students who used toilets for defecation in a primary school in the United Kingdom were statistically significantly more likely to develop Hepatitis A due to inadequate sanitation facilities [46]. On investigation, the school involved in the outbreak was found to lack toilet paper, hand towels, and soap for handwashing [46]. Hughes et al., studied sanitation in the Pacific Islands and reported a decrease in the risk for helminthic infections when children have increased access to water for handwashing and relieving wastes [42]; reporting, that, regardless of water quality, 
children who attend schools without water supply are four times more likely to contract helminthiases than children who attend schools with water supply [42].

\section{Discussion}

The school environment is an important sector to explore due to the social and health influences schools have on children [4]. In addition, the school environment is important for interventions aimed at mitigating infectious diseases spread because children may be introduced to more, and more strains of pathogens in the school, due to the fact that more children are present, in contact with, and using the facilities [6]. This exposure makes the school environment efficacious for performing infectious diseases interventions based on water, hygiene, and sanitation [6].

In comparing the efficacy of interventions conducted in developing and developed settings, and between regions within these categories, differences in results may be partly explained by varying baseline rates of disease. In similar studies on provision of water for handwashing, Rosen et al., in Israel found no significant changes in rates of illness or absenteeism, while similar studies in China and Egypt noted significant changes in rates of illness [30,33,35]. A feasible explanation for differences in these findings is the variation in prevalence of target illnesses between particular regions at the start of the intervention. Differences in the effect of an intervention in varying areas may be due to confounders that are best controlled for using blinding and randomized control trials. The future use of more high quality epidemiological studies such as this will control for confounders and elucidate the effects of water and sanitation in schools across diverse regions and nations.

The scope of our review with respect to water and sanitation facilities related to management of menstruation in schools was limited. Our criteria excluded papers related to the availability of sanitary napkins in schools. Though there is a large body of evidence within this field, and the outcomes related to it are critical in understanding the role of menstruation on school performance and absenteeism, it was outside the scope of this review. The available evidence supports the claim that a lack of water and sanitation facilities to manage menstruation in schools leads to discomfort and avoidance of school during menstruation. Freeman et al., have shown a decrease in absenteeism among girls after water and hygiene interventions [4]. This is particularly significant in light of high drop-out rates among young women in many developing countries [54]. The relationship between education and women's health, economic success and educational status has been documented [55]. Measures that enable women and girls to continue attendance in educational environments are essential to achieving the Millennium Development Goals of universal education and promoting women's gender equality and empowerment.

This review revealed areas for future research. Future studies should examine the relationship between drinking water and sanitation provision in schools. It has been suggested in the literature that a link may exist between unwillingness to drink water at school in order to avoid using unsanitary school toilets [50]. This interaction could lead to insufficient hydration and corresponding health effects [50]. In addition, chemical contaminants such as lead have the potential to impact children's development, yet little research exists on their prevalence in schools. This is particularly important in resource-poor settings, considering that all studies on this topic were conducted in the United States. In addition, it is unclear whether interventions in the school have the potential to impact the hygiene 
behaviors of caregivers at home. Blanton et al., found a significant increase in household water treatment practices that was sustained over one year after their intervention in Kenya [17]. However in their study, Freeman and Clasen found no significant differences in household uptake of water treatment practices one year after their school intervention in India [27]. High quality studies of programs targeted at water and sanitation access in schools that monitor the costs, benefits, sustainability and long-term impact on student and caregiver behavior are areas that could be further explored to usefully supplement this body of literature.

Potential errors in study identification and inclusion were mitigated by including a secondary reviewer. As studies were limited in number, used diverse methods and metrics and were conducted in various countries, findings may not be generalizable. No attempt was made to weight the value of the findings of studies according to study quality.

The World Health Organization has issued guidelines for water, sanitation, and hygiene implementation in schools in low cost settings [56]. Implementation of these regulations at the national level could result in improved water and sanitation conditions in schools. Such regulations would serve to overcome barriers to education, particularly in low resource settings where schools, teachers, and administrators may not recognize the potential impact of water and sanitation on health and education.

\section{Conclusions}

This review identified the health and educational effects of water and sanitation in schools. The goal of the review was to catalogue and characterize existing studies in the field. The review concluded that studies document higher rates of infectious, gastrointestinal, neuro-cognitive and psychological illnesses where school children were exposed to inadequate water and sanitation facilities. Potential areas for future research were identified. The evidence of widespread inadequate facilities suggests that greater resources and attention need to be invested in this field by school management, bureaucrats and multilateral and civil society organizations.

The overall reasoning behind attention to water and sanitation in schools is logical. Respiratory and gastrointestinal diseases are one of the leading causes of death for children globally [57]. The evidence summarized in this paper supports there being a link between gastrointestinal and other diseases has important implications for children's health worldwide. In order to achieve universal access to education as a right for all children, the underlying factors of water and sanitation provision in the school environment and their impacts on health and educational outcomes must be addressed through more rigorous investigation, political attention, and effective intervention.

\section{Acknowledgements}

The authors would like to thank the librarians who assisted with the research associated with this publication, Eva Rehfuess of the University of Munich's Institute for Medical Informatics, Biometry and Epidemiology, Alan Kinlaw of the UNC Epidemiology Department, Claudia Gollop of UNC School of Information and Library Science, and Mark Sobsey of the UNC Environmental Sciences and Engineering Department for all of their support and assistance with this publication. The University of North Carolina at Chapel Hill's Libraries provided support for open access publication. 


\section{Conflict of Interest}

The authors declare no conflict of interest.

\section{References}

1. United Nations (UN). The Millennium Development Goals Report 2011; United Nations: New York, NY, USA, 2011.

2. Mathekgana, M.A.; Chauke, L.K.; Otieno, F.A. Improvement of environmental health and hygiene practices-Case study in the Northern province. Water Sci. Technol. 2001, 44, 109-117.

3. Haines, L.; Rogers, J. A study of drinking facilities in schools. Nurs. Times 2000, 96, 2.

4. Freeman, M.C.; Greene, L.E.; Dreibelbis, R.; Saboori, S.; Muga, R.; Brumback, B.; Rheingans, R. Assessing the impact of a school-based water treatment, hygiene and sanitation programme on pupil absence in Nyanza province, Kenya: A cluster-randomized trial. Trop. Med. Int. Health 2011, 17, 380-391.

5. World Health Organization (WHO). The World Health Report 2002, Reducing Risks, Promoting Healthy Life. Available online: http://www.who.int/whr/2002/en/whr02_en.pdf (accessed on 15 June 2012).

6. Koopman, J.S. Diarrhea and school toilet hygiene in Cali, Colombia. Am. J. Epidemiol. 1978, 107, 412-420.

7. Berkowitz, M. Survey of New Jersey schools and day care centers for lead in plumbing solder. Identification of lead solder and prevention of exposure to drinking water contaminated with lead from plumbing solder. Environ. Res. 1995, 71, 55-59.

8. Bryant, S.D. Lead-contaminated drinking waters in the public schools of Philadelphia. J. Toxicol. Clin. Toxicol. 2004, 42, 287-294.

9. Costa, R.A.; Nuttall, K.L.; Shaffer, J.B.; Peterson, D.L.; Ash, K.O. Suspected lead poisoning in a public school. Ann. Clin. Lab. Sci. 1997, 27, 413-417.

10. Hunter, M.L.; Chestnutt, I.G.; Evans, S.M.; Withecombe, A.C. Fluid for thought: Availability of drinks in primary and secondary schools in Cardiff, UK. Int. J. Paediatr. Dent. 2004, 14, 267-271.

11. Kaushik, A.; Mullee, M.A.; Bryant, T.N.; Hill, C.M. A study of the association between children's access to drinking water in primary schools and their fluid intake: Can water be 'cool' in school? Child Care Health Dev. 2007, 33, 409-415.

12. Loughridge, J.L.; Barratt, J. Does the provision of cooled filtered water in secondary school cafeterias increase water drinking and decrease the purchase of soft drinks? J. Hum. Nutr. Diet. 2005, 18, 281-286.

13. Muckelbauer, R.; Libuda, L.; Clausen, K.; Toschke, A.M.; Reinehr, T.; Kersting, M. Promotion and provision of drinking water in schools for overweight prevention: Randomized, controlled cluster trial. Pediatrics 2009, 123, e661-e667.

14. Patel, A.I.; Bogart, L.M.; Uyeda, K.E.; Rabin, A.; Schuster, M.A. Perceptions about availability and adequacy of drinking water in a large California school district. Prev. Chronic Dis. 2010, 7 , A39:1-A39:10. 
15. Sathyanarayana, S.; Beaudet, N.; Omri, K.; Karr, C. Predicting children’s blood lead levels from exposure to school drinking water in Seattle, Washington, USA. Ambul. Pediatr. 2006, 6, 288-292.

16. Wallis, E.M.; Dorman, K.B. Drinking water in schools. Public Health 1970, 84, 191-193.

17. Blanton, E.; Ombeki, S.; Oluoch, G.O.; Mwaki, A.; Wannemuehler, K.; Quick, R. Evaluation of the role of school children in the promotion of point-of-use water treatment and handwashing in schools and households-Nyanza province, Western Kenya, 2007. Am. J. Trop. Med. Hyg. 2010, 82, 664-671.

18. Chen, K.T.; Chen, C.J.; Chiu, J.P. A school waterborne outbreak involving both Shigella sonnei and Entamoeba histolytica. J. Environ. Health 2001, 64, 9-13.

19. Migele, J.; Ombeki, S.; Ayalo, M.; Biggerstaff, M.; Quick, R. Diarrhea prevention in a Kenyan school through the use of a simple safe water and hygiene intervention. Am. J. Trop. Med. Hyg. 2007, 76, 351-353.

20. O’Reilly, C.E.; Freeman, M.C.; Ravani, M.; Migele, J.; Mwaki, A.; Ayalo, M.; Ombeki, S.; Hoekstra, R.M.; Quick, R. The impact of a school-based safe water and hygiene programme on knowledge and practices of students and their parents: Nyanza province, Western Kenya, 2006. Epidemiol. Infect. 2008, 136, 80-91.

21. Abrahams, N.; Mathews, S.; Ramela, P. Intersections of 'sanitation, sexual coercion and girls' safety in schools'. Trop. Med. Int. Health 2006, 11, 751-756.

22. Jones, R.; Finlay, F. Sanitary towel provision and disposal in primary schools. Child Care Health Dev. 2001, 27, 85-92.

23. Menstrual Hygiene Subcommittee of the Medical Women's Federation. Supply and Disposal of Sanitary Towels in Schools. Lancet 1949, 1, 925-927.

24. Sommer, M. Where the education system and women's bodies collide: The social and health impact of girls' experiences of menstruation and schooling in Tanzania. J. Adolesc. 2010, 33, 521-529.

25. Bowen, A.; Ma, H.L.; Ou, J.M.; Billhimer, W.; Long, T.; Mintz, E.; Hoekstra, R.M.; Luby, S. A cluster-randomized controlled trial evaluating the effect of a handwashing-promotion program in Chinese primary schools. Am. J. Trop. Med. Hyg. 2007, 76, 1166-1173.

26. Burr, M.L.; Davis, A.R.; Zbijowski, A.G. Diarrhoea and the drought. Public Health 1978, 92, 86-87.

27. Freeman, M.C.; Clasen, T. Assessing the impact of a school-based safe water intervention on household adoption of point-of-use water treatment practices in Southern India. Am. J. Trop. Med. Hyg. 2011, 84, 370-378.

28. Lopez-Quintero, C.; Freeman, P.; Neumark, Y. Hand washing among school children in Bogota, Colombia. Am. J. Public Health 2009, 99, 94-101.

29. Rosen, L.; Manor, O.; Engelhard, D.; Brody, D.; Rosen, B.; Peleg, H.; Meir, M.; Zucker, D. Can a handwashing intervention make a difference? Results from a randomized controlled trial in Jerusalem preschools. Prev. Med. 2006, 42, 27-32.

30. Scott, E.; Vanick, K. A survey of hand hygiene practices on a residential college campus. Am. J. Infect. Control 2007, 35, 694-696. 
31. Talaat, M.; Afifi, S.; Dueger, E.; El-Ashry, N.; Marfin, A.; Kandeel, A.; Mohareb, E.; El-Sayed, N. Effects of hand hygiene campaigns on incidence of laboratory-confirmed influenza and absenteeism in schoolchildren, Cairo, Egypt. Emerg. Infect. Dis. 2011, 17, 619-625.

32. Barnes, P.M.; Maddocks, A. Standards in school toilets-A questionnaire survey. J. Public Health Med. 2002, 24, 85-87.

33. Durán-Narucki, V. School building condition, school attendance, and academic achievement in New York City public schools: A mediation model. J. Environ. Psychol. 2008, 28, 278-286.

34. Lundblad, B.; Hellstrom, A.L., Perceptions of school toilets as a cause for irregular toilet habits among schoolchildren aged 6 to 16 years. J. Sch. Health 2005, 75, 125-128.

35. Mwanri, L.; Worsley, A.; Masika, J. School and anaemia prevention: Current reality and opportunities-A Tanzanian case study. Health Promot. Int. 2001, 16, 321-331.

36. Samwel, M.; Gabizon, S. Improving school sanitation in a sustainable way for a better health of school children in the EECCA and in the new EU member states. Desalination 2009, 248, 384-391.

37. Upadhyay, V.; Mathai, J.; Reed, P.W. Primary school children: Access to toilets. Acta Paediatr. 2008, 97, 1546-1549.

38. Adegbenro, C.A. Effect of a school health programme on ensuring safe environments for primary school children. J. R. Soc. Promot. Health 2007, 127, 29-32.

39. Curin, K.; Pavic, S. Hygienic conditions in elementary and secondary schools in the county of Split-Dalmatia. Arh. Hig. Rada Toksikol. 1999, 50, 273-281.

40. Ebong, R.D. Environmental health knowledge and practice survey among secondary schoolchildren in Zaria, Nigeria. Environ. Health Perspect. 1994, 102, 310-312.

41. Fujiwara-Pichler, E.; Maddocks, A.; Barnes, P.M. Standards in school toilets: Do extra resources make a difference? J. Public Health (Oxf.) 2006, 28, 294-295.

42. Hughes, R.G.; Sharp, D.S.; Hughes, M.C.; Akauola, S.; Heinsbroek, P.; Velayudhan, R.; Schulz, D.; Palmer, K.; Cavalli-Sforza, T.; Galea, G. Environmental influences on helminthiasis and nutritional status among Pacific schoolchildren. Int. J. Environ. Health Res. 2004, 14, 163-177.

43. Jewkes, R.K.; O’Connor, B.H. Crisis in our schools: Survey of sanitation facilities in schools in bloomsbury health district. BMJ 1990, 301, 1085-1087.

44. Midzi, N.; Mtapuri-Zinyowera, S.; Mapingure, M.P.; Paul, N.H.; Sangweme, D.; Hlerema, G.; Mutsaka, M.J.; Tongogara, F.; Makware, G.; Chadukura, V.; et al. Knowledge attitudes and practices of grade three primary schoolchildren in relation to schistosomiasis, soil transmitted helminthiasis and malaria in Zimbabwe. BMC Infect. Dis. 2011, 11, doi:10.1186/1471-2334-11-69.

45. Perez, J. Minimum standards for school toilets are needed to improve child health. Nurs. Times 2010, 106, 30.

46. Rajaratnam, G.; Patel, M.; Parry, J.V.; Perry, K.R.; Palmer, S.R. An outbreak of hepatitis A: School toilets as a source of transmission. J. Public Health Med. 1992, 14, 72-77.

47. Thomas, M.E.; Tillett, H.E. Sonne dysentery in day schools and nurseries: An eighteen-year study in Edmonton. J. Hyg. (Lond.) 1973, 71, 593-602.

48. Udo, S.M.; Eja, M.E. Prevalence and antibiotic resistant Shigellae among primary school children in urban Calabar, Nigeria. Asia Pac. J. Public Health 2004, 16, 41-44. 
49. Ulukanligil, M.; Seyrek, A. Demographic and parasitic infection status of schoolchildren and sanitary conditions of schools in Sanliurfa, Turkey. BMC Public Health 2003, 3, 29, doi:10.1186/1471-2458-3-29.

50. Vernon, S.; Lundblad, B.; Hellstrom, A.L. Children's experiences of school toilets present a risk to their physical and psychological health. Child Care Health Dev. 2003, 29, 47-53.

51. United Nations (UN). Composition of Macro Geographical (Continental) Regions, Geographical Sub-Regions, and Selected Economic and Other Groupings. Available online: http://unstats.un.org/unsd/methods/m49/m49regin.htm (accessed on 15 April 2012).

52. Agency for Toxic Substances and Disease Registry (ATSDR). Lead (Pb) Toxicity: What Are the Physiologic Effects of Lead Exposure? Agency for Toxic Substances and Disease Registry: Atlanta, GA, USA, 2009.

53. World Health Organization (WHO). Guidelines for Drinking-Water Quality, 4th ed.; World Health Organization: Geneva, Switzerland, 2011.

54. Herz, B.; Sperling, G. What Works in Girls' Education: Evidence and Policies from the Developing World: A Report by Barbara Herz and Gene Sperling. Available online: http://www.cfr.org/education/works-girls-education-evidence-policies-developing-world-reportbarbara-herz-gene-sperling/p6974 (accessed on 15 April 2012).

55. Roudi-Fahimi, F.; Valentine, M. Empowering Women, Developing Society: Female Education in the Middle East and North Africa; Population Reference Bureau: Washington, DC, USA, 2003; pp. 1-7.

56. World Health Organization (WHO). Water, Sanitation and Hygiene Standards for Schools in Low-Cost Settings; WHO: Geneva, Switzerland, 2009.

57. World Health Organization (WHO). Global Status Report on Noncommunicable Diseases. Available online: http://www.who.int/nmh/publications_ncd_report_full_en.pdf (accessed on 15 June 2012.

(C) 2012 by the authors; licensee MDPI, Basel, Switzerland. This article is an open access article distributed under the terms and conditions of the Creative Commons Attribution license (http://creativecommons.org/licenses/by/3.0/). 